\title{
Gender Identity in Patients with Congenital Adrenal Hyperplasia
}

\author{
Maryam Razzaghy-Azar, ${ }^{1,2,}$, Sakineh Karimi, ${ }^{1}$ and Elham Shirazi ${ }^{1,3}$ \\ ${ }^{1}$ H. Ali-Asghar Children's Hospital, Iran University of Medical Sciences, Tehran, Iran \\ ${ }^{2}$ Metabolic Disorders Research Center, Endocrinology and Metabolism Molecular-Cellular Sciences Institute, Tehran University of Medical Sciences, Tehran, Iran \\ ${ }^{3}$ Mental Health Research Center, Tehran Institute of Psychiatry-School of Behavioral Sciences and Mental Health, Iran University of Medical Sciences, Tehran, Iran \\ "Corresponding author: Maryam Razzaghy-Azar, M.D., 193 H. Ali-Asghar Children's Hospital, East Dastgerdi Street, Modarress Exp. Way, 1919816766, Tehran, Iran. E-mail: \\ mrazar_md@yahoo.com
}

Received 2017 January 01; Revised 2017 May 23; Accepted 2017 July 02.

\begin{abstract}
Background: Sex assignment in infancy for patients with disorder of sex development (DSD) is a challenging problem. Some of the patients with congenital adrenal hyperplasia (CAH) have DSD that may affect their gender identity.

Objectives: The study aimed to assess gender identity in patients with $\mathrm{CAH}$.

Methods: In this study, 52 patients with CAH, including 22 prepubertal children and 30 adolescents and adults, were assessed using two separate gender identity questionnaires for children and adults based on the criteria of diagnostic and statistical manual of mental disorders, 5th edition.

Results: In the children group, compatibility was seen between gender identity and rearing gender. In the adult group, there were three cases of mismatching between gender identity and sex assignment composed of two females with poor control and one male with good control with 21-hydroxylase deficiency (21-OHD). Three girls with 11-hydroxylase deficiency (11-OHD) were reared as boy. Two of them with late diagnosis at 5 and 6 years of age had pseudoprecocious puberty. Parents and children did not accept to change the gender. One of them is 36 years old now, is depressed and unsatisfied with her gender, another girl is still child and has male sexual identity. One girl with 11-OHD and early diagnosis at birth with Prader 5 virilization but with good hormonal control was changed to female gender at 12 years of age when female sexual characteristics appeared; she is 34 -years-old now, married, and with two children, and she is satisfied with her gender.

Conclusions: In patients with $\mathrm{CAH}$, gender identity disorder is a rare finding. Hormonal control, social, familial, and religious beliefs have impacts on gender identity of these patients.
\end{abstract}

Keywords: Gender Identity, Congenital Adrenal Hyperplasia

\section{Background}

Congenital adrenal hyperplasia (CAH) is a group of autosomal recessive disorders caused by enzymatic defects in the corticosteroid synthesis pathway leading to an increase in the serum level of ACTH and adrenocortical hyperplasia (1). They are mainly resulted from mutations in the genes of the enzymes that mediate the biochemical steps of corticosteroids production from cholesterol by the adrenal glands such as 21-hydroxylase (2). These conditions involve excessive or deficient production of sex steroids and thus sometimes alter developing sex characteristics in affected fetus (3). One of the major clinical manifestations of this abnormality is disorder of sex development (DSD) that is characterized by initial difficulty in identifying the gender according to external genitalia (4). A long-standing and fundamental question for psychologists, sociologists, biologists, and many other scientists is "how differences in sex behavior arise?" and thereby, many studies have been conducted in different species of animals (5). Androgen plays a key role in the development of male sexual phenotype, behavior, sexual orientation, and gender identity (6). In this regard, an increase in the male hormones not only can lead to the change of external genitalia, but also may alter sexual behavior. Gender identity refers to an individual's subjective internal sense of being a male or a female. Usually, most children can label their gender identity by the age of 3 years. Gender identity remains stable over time, but it may change in a small number of persons (7). Adults with gender identity disorder find occupation for living as a person of the opposite sex that may be manifested by intense desire for social role of the opposite sex or by obtaining the physical appearance of the opposite sex through hormonal or surgical manipulation (8). In addition, these patients try to appear as a member of the opposite sex population (9). Different ideas about the time of sex assignment of a child with DSD exist; some psychologists have the opinion to postpone it after puberty and then to act according to the desire of the patient. Some authors say that it should be done according to the grade of virilization and the girls with more severe virilization should be reared as a boy. On the other hand, when a baby is born, the first question is about the gen- 
der, and mother imagines the life of her child according to the gender that may not be specified by the examination of external genitalia in patients with DSD. All the relatives in Iran ask about the gender of the newborn. Thus, DSD is a medical emergency for assignment of appropriate rearing gender of the neonate. It is difficult to change the gender of a child with $\mathrm{CAH}$ when is reared with the opposite sex not only due to social and personal aspects, but also because of the correcting genital surgery that had been done during infancy. This study has been done to clarify which factors affect gender identity in patients with $\mathrm{CAH}$, and what and when should be a gender assigned to a child with CAH and DSD.

\section{Methods}

Among 240 patients with CAH who were treated during 35 years, 52 patients who came to the clinic during the period of the study or those whose telephone numbers were available for recall were recruited sequentially into the study. Acceptance of participation in the study completely was optional. They participated in the interview after explaining the goal of the study and after obtaining their written informed consent. All the patients who were available accepted to participate in the interview except two sisters who were married and their husbands did not know anything about their problem. The study was approved by the ethics committee of the University by code 2044 and performed in accordance with the ethical standards of declaration of Helsinki and its later amendments. The patients were divided into two groups: prepubertal named as children group and pubertal or post pubertal named as adult group. The genetic gender of the cases is named $\mathrm{XX}$ for females and $\mathrm{XY}$ for males. They were diagnosed as CAH based on laboratory tests such as the levels of 17-hydroxyprogesterone, dehydroepiandrosteronesulfate, androstenedione, testosterone, sodium, potassium, plasma renin activity, aldosterone, cortisol and ACTH, and karyotype as well as clinical manifestations. The stage of virilization was determined by Prader scoring. The degree of virilization of the external genitalia in a female and undervirilization in a male was described by Prader in 1954 (10) (Stage 1: Only clitoromegaly, stage 2: Clitoromegaly, partial labioscrotal fusion and a funnelshaped urogenital sinus, urethral meatus and vaginal orifice are separately seen, stage 3: Increased phallus or clitoris size with parial labioscrotal fold fusion forming a single urogenital sinus in the perineoscrotal area with no labia minora, stage 4: further increased phallus or clitoris size with an orifice at the base of phallus or phallus like clitoris with perineal hypospadiasis, stage 5: female with normal male-appearing and penile urethra).
Two separate questionnaires of gender identity were filled by face-to-face interviews. The interviews were performed by an expert psychiatrist (the third author) in this field. The questionnaires are existed in the related sites (7, 11). They were designed for children and adults according to the criteria of DSM-5 (12). The reliability of the Persian questionnaires was determined acceptable by the Cronbach's alpha $(\alpha)$ coefficient of 0.955 for adolescents and adults and 0.726 for children (we had two Cronbach's alpha scores because of having two separate questionnaires).

The questionnaires demonstrated $100 \%$ sensitivity and $98.5 \%$ specificity in the cut-off point of 26 in males and $100 \%$ sensitivity and $100 \%$ specificity in the cut-off point of 35 in females. There was no time limit to complete the questionnaire and interviews. Information obtained in all the phases of the study remained confidential and the name of the patients was defined as "Codes".

\section{Results}

There were $18 \mathrm{XY}$ and $34 \mathrm{XX}$ in 52 patients. The age of the total patients was $19 \pm 10$ years (range, 5 - 37). In the $\mathrm{XY}$ group, the age was $20 \pm 7(10-37)$ years and in the XX group it was $18 \pm 11$ (5 - 37) years. The study subjects were composed of 22 cases in the children group (15 XX, $7 \mathrm{XY}$ ) with the mean age of $9 \pm 3$ years (range, 5 - 14 years) and 30 cases in the adult group (19 XX and $11 \mathrm{XY}$ ) with the mean age of $26 \pm 6$ years (17 - 37). The type of CAH is shown in Table 1. Prader staging of the patients is illustrated in Table 2.

\subsection{Gender Identity}

Two patients with lipoid adrenal hyperplasia who were 13 and 19 years of age and one patient with 17-hydroxylase deficiency (17-OHD) aged 13.2 years had 46, XY karyotype. They had complete female phenotype, rearing gender was female, and the testes were removed. Hormone replacement therapy has begun for them and they have had female gender identity without any problem until now. They have had a normal growth and preferred to wear girls' clothes. The questions special for their age showed preference of female gender in their lifestyle. In the children group, there was no case of gender identity mismatch with the gender selected at birth despite the Prader score of IV in 5 females and Prader score of V in 4 females. In the adult group, among patients with 21-hydroxylase deficiency (21OHD), one girl who was 33-years-old had strong body and she liked to do jobs that are more appropriate for men; but her gender identity was female and did not have any interest to homosexuality. A 28-year-old boy who had simple virilizing type of 21-OHD with karyotype of 46, XY and complete male phenotype expressed the preference of girl's 
Table 1. Frequency of Different Types of CAH in Study Subjects According to Age Groups and Karyotype

\begin{tabular}{|c|c|c|c|c|c|c|c|}
\hline \multirow[t]{2}{*}{ Type } & \multicolumn{3}{|c|}{$5-14 \mathrm{yr}$} & \multicolumn{3}{|c|}{$\geq 15 \mathrm{yr}$} & \multirow[t]{2}{*}{ Total } \\
\hline & $\mathbf{X Y}$ & $\mathbf{X X}$ & Total & $\mathbf{X Y}$ & $\mathbf{X X}$ & Total & \\
\hline 21- OHD & 4 & 10 & 14 & 6 & 14 & 20 & $34(65.4)$ \\
\hline 11 - OHD & 1 & 2 & 3 & 4 & 3 & 7 & $10(19.2)$ \\
\hline 3 - ВОНD & & 2 & 2 & & 2 & 2 & $4(7.7)$ \\
\hline Lipoid AH & 1 & 1 & 2 & 1 & & 1 & $3(5.8)$ \\
\hline 17 - OHD & 1 & & 1 & & & & $1(1.9)$ \\
\hline Total & 7 & 15 & 21 & 11 & 19 & 30 & 52 \\
\hline
\end{tabular}

Abbreviations: 3-BOHD, 3 beta hydroxysteroid dehydrogenase deficiency; AH, adrenal hyperplasia; OHD, hydroxylase deficiency.

Table 2. Prader Stage of Virilization in Females According to Age Groups

\begin{tabular}{|c|c|c|c|c|c|c|}
\hline \multirow[t]{2}{*}{ Age Groups } & \multicolumn{6}{|c|}{ Prader Stage, Frequency (Percent) } \\
\hline & $\mathbf{0}^{\mathbf{a}}$ & $\mathbf{1}$ & 2 & 3 & 4 & 5 \\
\hline $5-14$ years & $3(18.8)$ & $3(18.8)$ & $4(25)$ & $3(18.8)$ & $2(12.5)$ & $1(6.3)$ \\
\hline$\geq 15$ years & $3(15)$ & $4(20)$ & $3(15)$ & $4(20)$ & $3(15)$ & $3(15)$ \\
\hline
\end{tabular}

${ }^{\mathrm{a}}$ Two XY patients with lipoid adrenal hyperplasia are included.

clothes and cosmetics. In terms of the sexuality in adolescence, he tended to play the role of female but when Hood Sura Verses 77 - 83 from Quran about homosexuality were described for him by the first author and he understood the sin of this work, he decided to change his behavior. Two girls with salt-wasting type of 21-OHD and karyotype of XX had male gender identity during puberty. Both were assigned as female gender at birth and operated by genitoplasty at one year of age. They had female gender identity within childhood; however, at the age of puberty, their identity was shifted to male. In one of the patients, who was 27-years-old and had Prader 4 virilization before genitoplasty, the reason for identity shifting was expressed as failure in love with a boy. She believed that it is not fair to be a girl and she would like to wear boys' clothes; she had sexual relationship with her girlfriend without awareness of her family. Her sister is also affected to the same type of CAH and the same degree of Prader score of virilization that was repaired; but she has gotten married, has a child, and she is satisfied with her gender assignment. Another case had Prader 3 virilization before operation. She was on treatment with hydrocortisone and fludrocortisone but with very poor compliance and lost from followup for 2 and 3 years in 2 periods. In the last visit, 17-OH progesterone was high and clitoromegaly was noticed. She had severe desire to be a boy with an aggressive manner to parents and physician for requesting to change the gender by operation. She wore boy's clothes, expressed disgust of girl clothes, and had girlfriend relationship with the role of a boy. Hydrocortisone was changed to prednisolone with friendly recommendation to good compliance and 3 month waiting for decision of changing the gender (although it was not possible because of previous surgery). 17$\mathrm{OH}$ progesterone decreased after 3 months, and the mood of the patient unbelievably changed; she did plastic nose surgery, wore girl's dress, and her behavior changed completely.

In the 11-OHD group, one 6-year-old girl with Prader 3 virilization was reared as a boy. He came from a rural area without diagnosis. The parents were farmer and said that if their child gender changes, they will have to leave their village and they will lose their farm and relatives. In spite of psychological effort, they did not accept this change at all. The child had male gender identity so her uterus and gonads were removed by surgery.

Another patient who is a 34-year-old woman has 11OHD. She had Prader 5 virilization diagnosed at birth. No pediatric surgeon knew how to change the appearance of genitalia at that time. She was referred to a hospital for removing the uterus and ovaries; but because of the war situation of the hospitals, the surgeon mistakenly searched for testes with misdiagnosis of cryptorchidism and ended the operation with suspicion of anorchia without reporting to us. Therefore, she reared as a male until 12 years of age. She went to boy's school and wore boy's clothes. She was in good control by hydrocortisone with small normal 
phallus. At 12 years of age, breast development and one menstruation occurred and surgical report was requested from the hospital that revealed the story. The change of gender was suggested and with the help of parents, the patient accepted to change the gender easily. She was operated and changed to female phenotype that was possible at that time. She got married and she has two children now and is satisfied with her gender.

Another girl who had 11-OHD was reared as a boy. She was ignored for treatment until 6 years of age when Prader 4 of his virilization had progressed to Tanner (13) stage 3 of pseudo puberty and bone age was 11 years. His parents and the child did not accept sex reversal and the surgeon did not accept operation because of large clitoris similar to adult phallus. Therefore, she continued to be a boy so uterus and ovaries were removed. Now, she is 36years-old, her virilization did not progress, and regressed to some extent because of good control of CAH and not using testosterone properly. She has short stature $(147 \mathrm{~cm})$, is depressed, expresses regret, and cannot find an appropriate job. The patient has a younger brother and a sister with the same disorder. They had early diagnosis and early treatment with good compliance and they are satisfied with the selected gender compatible with their karyotype.

\section{Discussion}

Two of our patients with lipoid adrenal hyperplasia and one patient with 17-OHD had XY karyotype with complete female phenotype and female sex assignment at birth. They have female gender identity despite their karyotype. Therefore, karyotype does not have a role in gender identity. Two girls and one boy from 34 patients with 21OHD had gender identity opposite to their sex assignment. In the 21-OHD group, the boy with female behavior was on more exposure to androgen in intrauterine life than a normal fetus but he had social contact with boys who abused him. He changed his behavior when understood the sin of this work. One of the girls, who had male gender identity, was in poor control and with bad compliance. Her androgen levels were high. She surprisingly changed her behavior after good control of the disease. In our study, the girls with high stages of Prader scoring had female identity because they were in good control of their disease in spite of high intrauterine exposure to androgen. In fact, hormonal milieu after birth had more effect on gender identity than intrauterine hormones and chromosomal parameters. The control of the disease was very good in the girl with 11-OHD who reared as a boy. When breast development occurred, she accepted to be a girl unbelievably. Perhaps estrogen secretion from ovaries had some effects on her decision. There are a few studies on gender identity in patients with CAH. Slijper et al. (14) studied patients with CAH and found out that deviation of gender role was found in girls with CAH and girls with disorder of sex development. They explained that both social and biological factors such as pre and postnatal hormones and inability of parents to accept their child gender could have an influence on the deviation of sex identity. Lee et al. (15) showed that those extremely virilized 46, XX CAH patients who were reared as male with healthy social support demonstrated satisfactory levels of social and sexual function as adult male. Therefore, they suggest sex assignment of male for such patients when social and cultural environment are supportive. Nevertheless, our patient with Prader 5 virilization, who was reared as a boy and changed to female, is more satisfied with her life than the girl who reared as a boy and kept in male gender. The first one got married and she has two children; she does not need testosterone for being male and she has a normal female life while the second one is disappointed and unsatisfied with her life. In another study by Birnbaum et al. (16), 88\% of girls with $\mathrm{CAH}$ had total gender identity scores overlapping those of control girls. Some studies show that girls with CAH show increased male-typical play behavior in childhood and sexual un-satisfaction in adulthood (17-20). In these studies, the level of hormonal control of the disease is not described in the patients who had opposite gender identity and the type of surgery is important in sexual satisfaction, as well.

There are challenges on the time of sex assignment according to gender identity formation because of difficulty of net estimation of its correct time. However, it is suggested that the optimal time for gender identity formation is around 18 to 36 months of age. On the other hand, it is believed that more sex differences in brain structure become apparent in adolescence and during maturity period that depend on sex hormones. In the study on animals, both receptors for male and female genders exist in the brain, and pheromones have an impact on these centers, causing female or male behavior (5). The desire of parents to have a boy or a girl also may have an impact on the child gender identity and they sometimes lead their child to their desire gender as observed in the case of one of our patients. Although in our study there were a few patients with opposite gender identity, every patient has an unusual story that does not occur routinely and makes a good experience for us.

\subsection{Conclusion}

Gender assignment of patients with CAH should be done as soon as possible before knowing of the people around. Good hormonal control, familial, social, and re- 
ligious beliefs have effects on sexual behavior and gender identity of patients with CAH.

\section{Acknowledgments}

None declared.

\section{Footnotes}

Authors' Contribution: Maryam Razzaghy-Azar, M.D. professor of pediatrics, pediatric endocrinology, and metabolism, Iran University of Medical Sciences has seen, diagnosed, and treated these patients since entry until now, she analyzed the data, edited, and shared in writing the paper; Sakineh Karimi, M.D. specialty in pediatrics, subspecialty in pediatric endocrinology, and metabolism collected the data, invited the patients, supervised the filling out of the questionnaires, and shared in writing the paper; Elham Shirazi is a psychiatrist and directed the preparation of the Persian version of the questionnaires and the process of their psychometric assessment.

Consent: Written informed consent was obtained from the patients for the publication of this paper. They knew that are participating in a research about gender identity. The name of the patients was confidential and the questionnaires were filled out by codes. The study was approved by the ethics committee of Iran University of Medical Sciences and performed in accordance with the ethical standards of declaration of Helsinki and its later amendments.

Financial Disclosure: The authors declare that there is no conflict of interest that could be perceived as prejudicing the impartiality of the research reported.

Funding/Support: This research did not receive any specific grant from any funding agency in the public, commercial, or not-for-profit sector.

\section{References}

1. Milunsky A, Milunsky J. Genetic disorders and the fetus: Diagnosis, prevention and treatment. John Wiley Son. 2010:600.

2. Merke DP. Approach to the adult with congenital adrenal hyperplasia due to 21-hydroxylase deficiency. J Clin Endocrinol Metab. 2008;93(3):653-60. doi:10.1210/jc.2007-2417. [PubMed: 18326005].

3. Witchel SF. Nonclassic congenital adrenal hyperplasia. Curr Opin Endocrinol Diabetes Obes. 2012;19(3):151-8.

4. Auchus RJ, Miller WL. Congenital adrenal hyperplasia-more dogma bites the dust. J Clin Endocrinol Metab. 2012;97(3):772-5. doi: 10.1210/jc.2012-1080. [PubMed: 22392955].
5. Dulac C, Kimchi T. Neural mechanisms underlying sex-specific behaviors in vertebrates. Curr Opin Neurobiol. 2007;17(6):675-83. doi: 10.1016/j.conb.2008.01.009. [PubMed:18343651].

6. Meyer-Bahlburg HF, Gruen RS, New MI, Bell JJ, Morishima A, Shimshi $M$, et al. Gender change from female to male in classical congenital adrenal hyperplasia. Horm Behav. 1996;30(4):319-32. doi: 10.1006/hbeh.1996.0039. [PubMed: 9047260].

7. Gender Identity Disorder in Children. . Available from: http://www. ifge.org/302.6_Gender_Identity_Disorder_in_Children.

8. Woelfle J, Hoepffner W, Sippell WG, Bramswig JH, Heidemann P, Deiss $\mathrm{D}$, et al. Complete virilization in congenital adrenal hyperplasia: clinical course, medical management and disease-related complications. Clin Endocrinol (Oxf). 2002;56(2):231-8. [PubMed: 11874415].

9. Merke DP, Bornstein SR. Congenital adrenal hyperplasia. Lancet. 2005;365(9477):2125-36. doi: 10.1016/S0140-6736(05)66736-0. [PubMed:15964450].

10. Prader A. Der GenitalbefundbeimPseudohermaphroditismusfeminimusdes kongenitalenadrenogenitalen syndrome. Helve Paediat Acta. 1954;3(231).

11. Gender Identity Disorder in Adolescents or Adults. . Available from: http://www.ifge.org/302.85_Gender_Identity_Disorder_in_ Adolescents_or_Adults.

12. Gender dysphoria.. American psychiatric association. Diagnostic and statistical manual of mental disorders. 5th ed. 1. Washington, DC: American Psychiatric Publishing; 2013. pp. 451-60.

13. Marshall WA, Tanner JM. Variations in pattern of pubertal changes in girls. Arch Dis Child. 1969;44(235):291-303. [PubMed: 5785179].

14. Slijper FM, Drop SL, Molenaar JC, de Muinck Keizer-Schrama SM. Longterm psychological evaluation of intersex children. Arch Sex Behav. 1998;27(2):125-44. [PubMed: 9562897]

15. Lee PA, Houk CP. Review of Outcome Information in 46,XX Patients with Congenital Adrenal Hyperplasia Assigned/Reared Male: What Does It Say about Gender Assignment? Int J Pediatr Endocrinol. 2010;2010:982025. doi: 10.1155/2010/982025. [PubMed: 21197442].

16. Berenbaum SA, Bailey JM. Effects on gender identity of prenatal androgens and genital appearance: evidence from girls with congenital adrenal hyperplasia.J Clin Endocrinol Metab. 2003;88(3):1102-6. doi: 10.1210/jc.2002-020782. [PubMed:12629091].

17. Hines M, Brook C, Conway GS. Androgen and psychosexual development: core gender identity, sexual orientation and recalled childhood gender role behavior in women and men with congenital adrenal hyperplasia (CAH). J Sex Res. 2004;41(1):75-81. doi: 10.1080/00224490409552215. [PubMed: 15216426].

18. Wong WI, Pasterski V, Hindmarsh PC, Geffner ME, Hines M. Are there parental socialization effects on the sex-typed behavior of individuals with congenital adrenal hyperplasia? Arch Sex Behav. 2013;42(3):38191. doi: 10.1007/s10508-012-9997-4. [PubMed: 22810998].

19. Bin-Abbas B, Al-Humaida D, Al-Sagheir A, Qasem E, Almohanna M, Alzahrani AS. Divergent gender identity in three siblings with 46XX karyotype and severely virilizing congenital adrenal hyperplasia caused by a novel CYP11B1 mutation. Endocr Pract. 2014;20(10):e191-7. doi: 10.4158/EP14179.CR. [PubMed: 25100385].

20. Pasterski V, Zucker KJ, Hindmarsh PC, Hughes IA, Acerini C, Spencer D, et al. Increased Cross-Gender Identification Independent of Gender Role Behavior in Girls with Congenital Adrenal Hyperplasia: Results from a Standardized Assessment of 4- to 11-Year-Old Children. Arch Sex Behav. 2015;44(5):1363-75. doi: 10.1007/s10508-014-0385-0. [PubMed: 25239661]. 